\title{
Aplikasi Startup rekomendasiin.com dengan Fitur Perekomendasian Berbasis SPK dengan Metode SAW
}

\author{
Rizqi Pratama, Eko Prasetyo, Arif Rinaldi, Ibnu Rusdi \\ email: rizqi.mailsos@gmail.com, ekkopras99@gmail.com, arifrinaldi68@gmail.com,ibnu.ibr@nusamandiri.ac.id \\ Universitas Nusa Mandiri
}

\begin{abstract}
Abstrak
Pada saat ini sudah banyak ecommerce dan banyak produk yang ditawarkan, apalagi produk IT, namun demikian pemilihan produk IT sangatlah tricky dimana sekarang pada produk IT memiliki spesifikasi yang sangat berdekatan. Agar pemilihan produk IT tersebut tepat dan sesuai maka haruslah dibuat sebuah pendukung keputusan. serta dengan pertumbuhan pengguna ponsel diindonesia membuat bisnis model startup menjadi pilihan yang bagus. Melalui metode sistim pendukung keputusan dengan algoritma simple additive weighting, dan juga dalam pengembangan aplikasi menggunakan metodologi waterfall atau SDLC, serta menggunakan permodelan business model canvassing (BMC) untuk pembuatan model bsinis. Maka dari metode metode diatas disusun dan digabungkan menghasilkan sebuah startup toko online yaitu rekomendasiin.com yang menyediakan fitur sistim perekomendasian sesuai dengan keinginan atau kebutuhan sipengguna yang berbasiskan sistim pendukung keputusan dengan metode simple additive weighting.
\end{abstract}

Kata Kunci: Ecommerce, Startup, Simple Additive Weighting, Waterfall.

\section{Pendahuluan}

Pada saat ini telah banyak e-commerce dan telah banyak juga produk yang ditawarkan, khususnya produk it. Dan banyak dari produk tersebut memiliki spesifikasi yang berdekatan.

Tidak adanya fitur perekomendasian yang sesuai keinginan atau kebutuhan sipengguna, maka hal-hal tersebutlah yang sering membuat pembeli mengalami kesulitan dalam pemilihan barang [1], [2].

Ini adalah peluang baru dimana belum adanya ecommerce yang menyediakan fitur perekomendasian. Dan juga karena pertumbuhan pengguna internet dindonesia yang besar, membuat model bisnis startup memiliki peluang sangat besar di indonesia, [3].

Untuk melakukan perekomendasian kami menggunakan algoritma sistim pendukung keputusan dengan metode simple additive weighting (SAW), metode tersebut menggunakan penjumlahan yang terbobot dengan hasil akhir sebuah perangkingan dari setiap alternatif kebutuhan. Dari algoritma dan metode tersebut yang membutuhkan variable bobot, alternatif, dan kriteria, yang dimana alternatif dapat diambil dari barang dan kriteria dapat diambil dari spesifikasi barang.

Maka dari hal tersebut tersisa variable bobot yang harus kami cari sumbernya, maka dari sini kami mendapatkan hipotesis bahwa variable bobot bisa diisi dengan kebutuhan yang dapat menentukan hasil akhir perangkingan setiap alternatif kebutuhan, yang akan digunakan dalam sistim perekomendasian rekomendasiin.com yang akan kami uji selanjutnya.

\section{Metode Penelitian}

Metode waterfall adalah metode adalah metode standar yang biasanya digunakan dalam pembuatan aplikasi, yang secara berurutan terdiri dari analisis, desain, koding, pengujian, dan pengoperasian [4]

Dalam Software Development Life Cycle Metode Waterfall tidak seperti metode Rapid Aplication Developement (RAD) yang mana aplikasi akhir bisa dirilis pada tahapan apapun melainkan hanya bisa kelseluruhan tahapan sudah dilakukan [4], Tetapi metode waterfall ini lebih cocok digunakan dalam pengembangan aplikasi ini, dimana harus secara terurut proses pengembangannya.

Dikarenakan project ini juga digunakan dalam skripsi kami maka dalam pengembangan ini harus measureable dalam artian pengembangannya harus pasti setiap tahapnya, tidak berubah ubah dalam rancangannya, supaya dalam segi penyusunan skripsi dan pengembangan aplikasinya dapat sesuai dengan milestone atau target waktu project yang sudah ditentukan. 


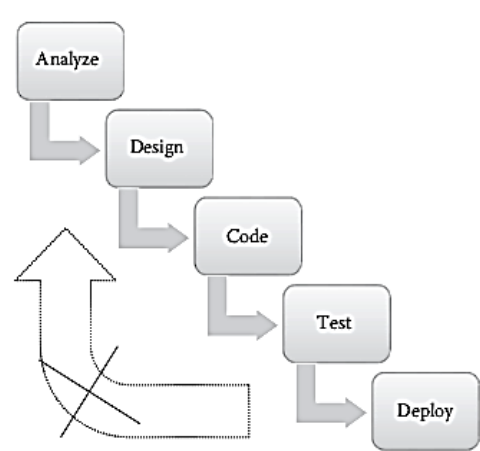

Waterfall - Unidirectional

Gambar 1. Metode Waterfall

Sesuai gambar diatas, berikut ini adalah tahapan dalam pengembangan aplikasi menggunakan metode waterfall.

1) Analyze atau analisa

Didalam analisa kami mengamati kebutuhan kebutuhan yang dibutuhkan dalam pengembangan aplikasi, mulai dari spesifikasi kebutuhan sistem, langkah langkah yang akan dilakukan, dan yang lainnya.

2) Design atau perancangan

Didalam rancangan kami merancang prototype aplikasi, bisa berupa rancangan user interface, rancangan database, algoritma, dan yang lainya.

3) Code atau koding

Didalam tahap ini kami menerapkan hasil rancangan yang telah kami buat, dalam bentuk sebuah source code, dengan bahasa pemrograman php untuk web dan java untuk android.

4) Test atau pengujian

Sebelum aplikasi siap dipublikasi, harus melakukan serangkaian testing, metode yang kami gunakan adalah metode blackbox.

5) Deploy atau pengoperasian

Aplikasi yang kami buat adalah aplikasi web dan android, maka dari itu kami akan hosting pada penyedia hosting, dan untuk android kami menggunakan android app market yaitu playstore untuk mempublikasikan aplikasi kami, supaya bisa didownload lalu di operasikan atau dijalankan.

\section{Hasil dan Pembahasan}

Rekomendasiin.com adalah startup toko online yang menawarkan fitur perekomendas- ian berdasarkan kebutuhan atau keinginan sipengguna, adapun tinjauan startup ini didalam uraian Analisa $B M C$ berikut ini:

1. Customer Segment

Pelanggan adalah inti dari sebuah usaha, tanpa pelanggan tidak ada yang membeli produk kita, dalam hal ini segmentasi pelanggan yang akan dituju startup ini adalah segnmentasi khusus saja, yaitu orang orang yang concern atau betul betul memperhatikan kesesuaian produk yang dibeli dan hasil yang didapat, dan juga orang orang yang sering binggung dalam memutuskan membeli barang dalam hal ini produk it.

2. Value Propositions

Value propositions yang diberikan startup ini adalah dalam bentuk jasa, yaitu perekomendasian barang, secara tidak langsung ini adalah sebuah bundling dari sebuah barang yang akan dijual, namun bundlingnya diberikan diawal secara free alias gratis. Dan berbagai kuntungan yang akan didapatkan oleh pelanggan nantinya, seperti promo promo dan sebagainya.

3. Channel

Channel menghubungkan value propositions kepada segmen pelanggan yang dituju, dalam hal ini saluran yang kami gunakan adalah pemasaran online atau digital marketing menggunakan web rekomendasiin.com dan juga menggunakan aplikasi yang sudah ada yang bisa diunduh melalui playstore.

4. Customer Relationship

Startup ini adalah startup baru, yang artinya belum banyak orang yang tau, maka dari itu kami akan menggunakan sosial media dalam menjangkau pelanggan dan calon pelanggan kami, dan juga internet advertising seperti google ads, AdChoices dan lain lain dalam menjangakau pelanggan yang lebih luas lainnya.

\section{Revenue Stream}

Sumber pendapatan adalah berasal dari margin penjualan dan dan komisi penjualan (bila menggunakan kerjasama konsinyasi).

6. Key Resources

Aset aset sebagai agar perusahaan dapat menawarkan sesuatu produk haruslah dalam satu paket, namun secara garis besar key resource yang inti dalam startup ini 
adalah produk yang ditawarkan yaitu handphone, supplier, website, dan aplikasi.

\section{Key Activities}

Akivitas inti dari startup ini adalah penjualan (sales) online, tapi lebih dari itu startup ini juga melakukan pemasaran online (digital marketing).

8. Key Partnership

Hubungan yang baik menghasilkan usaha yang baik juga, dalam menjalin usaha tebtunya dibutuhkan partner, kami menjalin kemitraan besrama vendor vendor distributor resmi dan beberapa toko unofficial produk yang tidak ada didalam negeri agar dapat menyuplai kebutuhan produk yang akan kami jual.

9. Cost Structure

Sartup ini mengandalkan margin penjualan dalam memperoleh keuntungannya, maka startup ini berdasarkan kepada cost driven startup yaitu startup yang cenderung menekan biaya supaya mendapatkan margin yang optimal.

Untuk menguji hipoteis kami bahwa variable bobot bisa diisi dengan kebutuhan yang dapat menentukan hasil akhir perangkingan setiap alternatif kebutuhan, maka kami lakukan dengan cara sederhana yang sudah dijelaskan pada bab sebelumnya. Pada kasus ini kami mengobservasi terhadap teman kami ketika sedang meminta saran kepada kami, dan kami bandingan dengan teman yang lainnya yang meminta saran tentang kebutuhan dan keinginan mereka, sesuai yang mereka ceritakan bahwa mereka menginginkan sesuatu dan mereka meminta saran untuk menyelesaikan permasalahan mereka, yaitu pemilihan barang yaitu handphone. Berikut ini tahap tahapannya:

Tahap ke-1, kami perlu menentukan apa yang termasuk alternatif, kriteria, cost, benefit, dan bobot.

Tabel 1. Alternatif dan Kriteria

\begin{tabular}{|l|l|}
\hline \multicolumn{2}{|c|}{ Tabel Alternatif dan Kriteria } \\
\hline Alternatif (A) & $\begin{array}{l}\text { Handphone dari berbagai } \\
\text { macam merek }\end{array}$ \\
\hline Kriteria (C) & $\begin{array}{l}\text { Spesifikasi handphone yang } \\
\text { dapat dibandingkan (Harga, } \\
\text { SoC, Ram, Rom, Camera, } \\
\text { Battrai ) }\end{array}$ \\
\hline
\end{tabular}

Table 2 Tabel Cost dan Benefit

\begin{tabular}{|l|l|}
\hline \multicolumn{2}{|c|}{ Tabel Cost dan Benefit } \\
\hline Kriteria Cost & $\begin{array}{l}\text { Apa yang harus dibayar atau } \\
\text { dikeluarkan (Harga) }\end{array}$ \\
\hline Kriteria Benefit & $\begin{array}{l}\text { Keuntungan (SoC, Ram, Rom, } \\
\text { Camera, Battrai) }\end{array}$ \\
\hline
\end{tabular}

Dari tabel diatas, konstanta dari setiap variabelnya akan kami dapatkan dari situs penyedia data, yang dilakukan dengan cara benchmark (menguji sesuatu dengan standar tertentu) yang dimana mereka sudah menguji setiap kriteria dari setiap alternatif yang ada. Penyedia datanya antara lain gsmarena.com, antutu.com, nanoreview.net \& dxomark.com, masing masing memiliki data untuk kebutuhan yang berbeda, dan kemudian data ini akan kami masukan kedalam database barang kami.

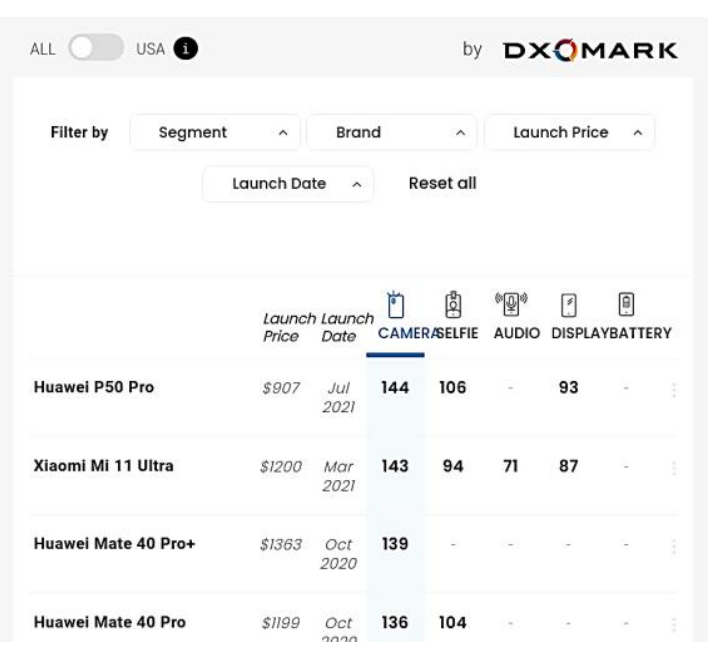

Gambar 2. Contoh data benchmark kamera dari Dxomarx

Tahap ke-2, selanjutnya kami mencari variable bobot dengan mengobservasi percakapan dengan teman kami. Teman yang pertama menginginkan handphone dengan hasil fotografi yang baik dengan harga maksimal $\mathrm{Rp}$ 4.500.000 sedangkan teman yang ke dua menginginkan handphone dengan performa gaming yang baik dengan harga maksimal $\mathrm{Rp}$ 4.500.000. Kami sebagai teman yang berlaku sebagai pakar, kami haruslah menentukan bobot atau hal yang harus dipentingkan pada spesifikasi handphone yang akan kami rekomendasikan. Maka dari hal tersebut kami menentukan variable bobot dalam sistim pendukung keputusan. Dimana bobot atau hal 
yang harus dipentingkan setiap orang bisa berbeda, berikut bobot yang diperoleh :

Tabel 3. Penentuan Bobot (Data Mentah)

\begin{tabular}{|c|c|c|c|c|c|c|c|c|c|}
\hline \multicolumn{7}{|c|}{ Tabel Penentuan Bobot (Data Mentah) } \\
\hline & \multicolumn{5}{|c|}{ Kriteria } \\
$\begin{array}{c}\text { Subye } \\
\text { k }\end{array}$ & $\begin{array}{c}\text { Keingina } \\
\text { Kebutuh } \\
\text { an }\end{array}$ & Alternatif & Harga & SoC & Ram & Rom & $\begin{array}{c}\text { Came } \\
\text { ra }\end{array}$ & Battrai & $\begin{array}{c}\text { Jumlah } \\
\text { bobot }\end{array}$ \\
\hline $\begin{array}{c}\text { Teman } \\
\text { 1 }\end{array}$ & Gaming & Handphone & 100 & 40 & 25 & 10 & 5 & 20 & 200 \\
\hline $\begin{array}{c}\text { Teman } \\
2\end{array}$ & Fotografi & Handphone & 100 & 10 & 10 & 25 & 35 & 20 & 200 \\
\hline
\end{tabular}

Data diatas menggunakan skala 0-200 maka supaya sesuai dengan kaidah metode saw dimana jumlah bobot dari sebuah alternatif harus $1, \quad \sum w_{i}=1$. maka kami menyederhanakannya dengan membaginya dengan 200, dan mendapatkan penyederhanaannya menjadi:

Tabel 4. Penentuan Bobot (Data disederhanakan)

\begin{tabular}{|c|c|c|c|c|c|c|c|c|c|}
\hline \multicolumn{10}{|c|}{ Tabel Penentuan Bobot (Data telah disederhanakan) } \\
\hline \multirow[b]{2}{*}{ Subyek } & \multirow{2}{*}{\begin{tabular}{|c|} 
Keingina \\
$\mathbf{n} /$ \\
Kebuttuha \\
$\mathbf{n}$
\end{tabular}} & \multirow[b]{2}{*}{ Alternatif } & \multicolumn{6}{|c|}{ Kriteria } & \multirow{2}{*}{$\begin{array}{c}\text { Jumlah } \\
\text { bobot }\end{array}$} \\
\hline & & & Harga & Soc & Ram & Rom & $\underset{\mathbf{a}}{\text { Camer }}$ & Battral & \\
\hline \begin{tabular}{|c|} 
Teman \\
1
\end{tabular} & Gaming & Handphone & 0.500 & 0.200 & 0.125 & 0.050 & 0.025 & 0.100 & 1.000 \\
\hline $\begin{array}{c}\text { Teman } \\
2\end{array}$ & Fotografl & Handphond & 0.500 & 0.050 & 0.050 & 0.125 & \begin{tabular}{|l|}
0.175 \\
\end{tabular} & 0.100 & 1.000 \\
\hline
\end{tabular}
normalisasi, Ditahap ini sebuah alternatif harus sudah ditentukan, alternatifnya adalah data barang yang diambil dari database barang kami dan nilai dari kriteria diambil dari situs penyedia data yang telah disebutkan diatas.

Tabel 5. Alternatif (Data Mentah)

\begin{tabular}{|c|c|c|c|c|c|c|}
\hline \multicolumn{7}{|c|}{ Tabel Alternatif (Data Mentah) } \\
\hline & Kriteria $* * *$ \\
\hline & Cost & Benefit & Benefit & Benefit & Benefit & Benefit \\
\hline Alternatif ** & C1 Harga * & C2 SoC & $\begin{array}{c}\text { C3 } \\
\text { Ram }\end{array}$ & $\begin{array}{c}\text { C4 } \\
\text { Rom }\end{array}$ & $\begin{array}{c}\text { C5 } \\
\text { Camera }\end{array}$ & $\begin{array}{c}\text { C6 } \\
\text { Battrai }\end{array}$ \\
\hline Realme 8 Pro & 4499000 & 171415 & 8 & 128 & 89 & 4500 \\
\hline Vivo V19 (256) & 4200000 & 117743 & 8 & 256 & 90 & 4500 \\
\hline Realme 7 Pro & 4000000 & 171415 & 8 & 128 & 79 & 4500 \\
\hline Oppo Reno 5 & 4200000 & 171415 & 8 & 128 & 88 & 4310 \\
\hline $\begin{array}{c}\text { Samsung Galaxy } \\
\text { A51 }\end{array}$ & 4399000 & 104687 & 8 & 128 & 87 & 4000 \\
\hline
\end{tabular}

* harga didapatkan dari database barang

** database barang didapatkan dari berbagai berbagai referensi yang ada pada tahun 2021

*** kriteria didapatkan dari sumber yang sudah disebutkan diatas.

Dari data-data diatas kita masukan rumus sebagai berikut :

$r_{i j}=\frac{\operatorname{Min}_{i} x_{i j}}{x_{i j}}$ jika atribut dari kiteria adalah cost. $r_{i j}=\frac{x_{i j}}{\operatorname{Max}_{i} x_{i j}}$ Jika atribut kriterianya adalah benefit.

Kita akan akan masukan rumus untuk baris 1 kolom kritera 1 hingga kiriteria 6 sebagai berikut:

$$
\begin{array}{lr}
r_{11}=\frac{4200000}{4499000}=0,93 & r_{12}=\frac{171415}{171415}=1,0 \\
r_{13}=\frac{8}{8}=1,0 & r_{14}=\frac{128}{256}=0,5 \\
5 r_{15}=\frac{89}{90}=0,988 & r_{16}=\frac{4500}{4500}=1,0
\end{array}
$$

Dari contoh perhitungan diatas kita akan mendapatkan nilai data yang

\begin{tabular}{|c|c|c|c|c|c|c|}
\hline \multicolumn{7}{|c|}{ Tabel Alternatif (Data Ternormalisasi) } \\
\hline & & & Kriteria & & & \\
\hline & Cost & Benefft & Benefft & Benefft & Benefft & Benefft \\
\hline Alternatif & C1 Harga & $\mathrm{C} 2 \mathrm{SoC}$ & C3Ram & C4 Rom & C5 Camera & C6 Battral \\
\hline Realme 8 Pro & 0.93354 & 1.00000 & 1.00000 & 0.50000 & 0.98889 & 1.00000 \\
\hline Vivo V19 (250) & 1.00000 & 0.68689 & 1.00000 & 1.00000 & 1.00000 & 1.00000 \\
\hline Realme 7 Pro & 0.91324 & 1.00000 & 1.00000 & 0.50000 & 0.87778 & 1.00000 \\
\hline Oppo 5 & 0.97697 & 1.00000 & 1.00000 & 0.50000 & 0.97778 & 0.95778 \\
\hline Samsung Galaxy A51 & 0.95476 & 0.61072 & 1.00000 & 0.50000 & 0.96667 & 0.88889 \\
\hline
\end{tabular}
ternormalisasi sebagai berikut:

Tabel 6. Alternatif (Data Ternormalisasi)

Tahap ke-4, selanjutnya kita masuk pada tahapan akhir yaitu perangkaian bobot, ditahap ini kami hanya menampilkan perhitungan sistem pengambilan keputusan untuk teman 1 saja yaitu gaming dengan maksimum harga Rp 4.500.000. Selanjutnya kita akan lakukan perangkaian dengan rumus $V_{i}=$ $\sum_{j=i}^{n} w_{j} r_{i j}$ dimana data kita peroleh dari data yang telah ternormalisasi diatas dengan bobot yang telah kita tentukan ditahap pertama.

Tabel 7. Bobot Teman 1

\begin{tabular}{|c|c|c|c|c|c|c|c|c|c|}
\hline \multicolumn{7}{|c|}{ Tabel bobot teman 1 } \\
\hline \multirow{2}{*}{$\begin{array}{c}\text { Subye } \\
\text { k }\end{array}$} & $\begin{array}{c}\text { Keingina } \\
\text { n } \\
\text { Kebutuh } \\
\text { an }\end{array}$ & Alternatif & Harga & SoC & Ram & Rom & $\begin{array}{c}\text { Came } \\
\text { ra }\end{array}$ & Battrai & $\begin{array}{c}\text { Jumlah } \\
\text { bobot }\end{array}$ \\
\hline $\begin{array}{c}\text { Teman } \\
1\end{array}$ & Gaming & Handphone & 0.500 & 0.200 & 0.125 & 0.050 & 0.025 & 0.100 & 1.000 \\
\hline
\end{tabular}

$\mathrm{V} 1=(0,5 * 0,93)+(0,2 * 1)+(0,125 * 1)+$ $(0,05 * 0,5)+\left(0,025^{*} 0,98\right)+(0,1 * 1)=0,9414$ $\mathrm{V} 2=(0,5 * 1)+(0,2 * 0,68)+(0,125 * 1)+$ $(0,05 * 1)+(0,025 * 1)+(0,1 * 1)=0,9373$ $\mathrm{V} 3=(0,5 * 0,91)+\left(0,2^{*} 1\right)+(0,125 * 1)+$ $(0,05 * 0,5)+(0,025 * 0,87)+(0,1 * 1)=0,9285$ $\mathrm{V} 4=(0,5 * 0,97)+(0,2 * 1)+(0,125 * 1)+(0,05 * 0,5)$ $+(0,025 * 0,97)+(0,1 * 0,95)=0,9587$ $\mathrm{V} 5=(0,5 * 0,95)+(0,2 * 0,61)+(0,125 * 1)+(0,05 * 0$ $, 5)+(0,025 * 0,96)+(0,1 * 0,88)=0,8625$ 
Dari perhitungan diatas kita urutkan dari yang terbesar hingga yang terkecil dan mendapatkan hasil akhir sebagai berikut :

Tabel 8. perangkingan alternatif untuk teman 1

\begin{tabular}{|c|c|c|}
\hline \multirow{2}{*}{ Ranking } & \multicolumn{2}{|c|}{ Tabel perangkingan alternatif untuk teman 1 } \\
\cline { 2 - 3 } & Alternatif & Nilai \\
\hline 1 & Oppo 5 & 0.9587 \\
\hline 2 & Realme 8 Pro & 0.9414 \\
\hline 3 & Vivo V19 (256) & 0.9373 \\
\hline 4 & Realme 7 Pro & 0.9285 \\
\hline 5 & Samsung Galaxy A51 & 0.8625 \\
\hline
\end{tabular}

Dari tabel diatas kita bisa gunakan sebagai acuan dalam pengambilan keputusan untuk teman 1 dengan kebutuhan gaming. Beda halnya dengan teman 2 , dengan kebutuhan fotografi dengan bobot sebagai berikut:

Tabel 9. Bobot Teman 2

\begin{tabular}{|c|c|c|c|c|c|c|c|c|c|}
\hline \multicolumn{7}{|c|}{ Tabel bobot teman 2 } \\
\hline
\end{tabular}

Akan menghasilkan perangkingan seperti berikut :

Tabel 10. perangkingan alternatif untuk teman 2

\begin{tabular}{|c|c|c|}
\hline \multirow{2}{*}{ Ranking } & Tabel perangkingan alternatif untuk teman 2 \\
\cline { 2 - 3 } & Alternatif & Nilai \\
\hline 1 & Vivo V19 (256) & 0.9843 \\
\hline 2 & Oppo 5 & 0.9178 \\
\hline 3 & Realme 8 Pro & 0.9023 \\
\hline 4 & Samsung Galaxy A51 8GB & 0.8784 \\
\hline 5 & Realme 7 Pro & 0.8727 \\
\hline
\end{tabular}

lalu perbandinganya adalah :

Tabel 11. perbandingan perangkingan alternatif

\begin{tabular}{|c|c|c|c|c|}
\hline \multicolumn{5}{|c|}{ Tabel perbandingan perangkingan alternatif } \\
\hline \multirow[b]{2}{*}{ Ranking } & \multicolumn{2}{|c|}{ Teman 1 (Gaming) } & \multicolumn{2}{|c|}{ Teman 2 (Fotografi) } \\
\hline & Alternatif & Nilai & Alternatif & Nilai \\
\hline 1 & Oppo 5 & 0.9587 & Vivo V19 (256) & 0.9843 \\
\hline 2 & Realme 8 Pro & 0.9414 & Oppo 5 & 0.9178 \\
\hline 3 & Vivo V19 (256) & 0.9373 & Realme 8 Pro & 0.9023 \\
\hline 4 & Realme 7 Pro & 0.9285 & $\begin{array}{c}\text { Samsung Galaxy } \\
\text { A51 8GB }\end{array}$ & 0.8784 \\
\hline 5 & $\begin{array}{c}\text { Samsung } \\
\text { Galaxy A51 }\end{array}$ & 0.8625 & Realme 7 Pro & 0.8727 \\
\hline
\end{tabular}

Dari hasil perhitungan diatas maka kita dapat menyimpulkan bahwa setiap kebutuhan akan berbeda bobot kebutuhannya dan setiap bobot kebutuhan bisa menghasilkan perangkingan yang berbeda. Maka dari perhitungan ini diharapkan dapat membantu dalam proses pemilihan barang nantinya dan hipotesis yang ada sudah diuji pada tahap ini.

Aplikasi harus memenuhi ekspetasi dari penggunanya maka dari hal tersebut beberapa kebutuhan harus lah dapat diketahui, berikut ini adalah analisa kebutuhan dari pengguna aplikasi ini nantinya.

a) Pengguna anonim dapat melalukan perkomendasian.

b) Pengguna dapat mendaftar dan login.

c) Pengguna dapat menambahkan kekeranjang hasil perekomendasian.

d) Pengguna dapat menambahkan alamat

e) Pengguna bisa mengubah pengaturan akun.

f) Pengguna dapat menambahkan ke keranjang.

g) Pengguna dapat checkout barang yang sudah ada dikeranjang.

1) Halaman Depan

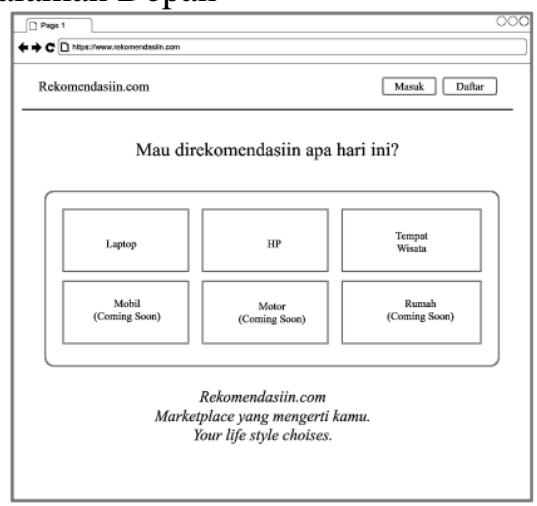

Gambar 3. Rancangan halaman depan

2) Pemilihan Kriteria

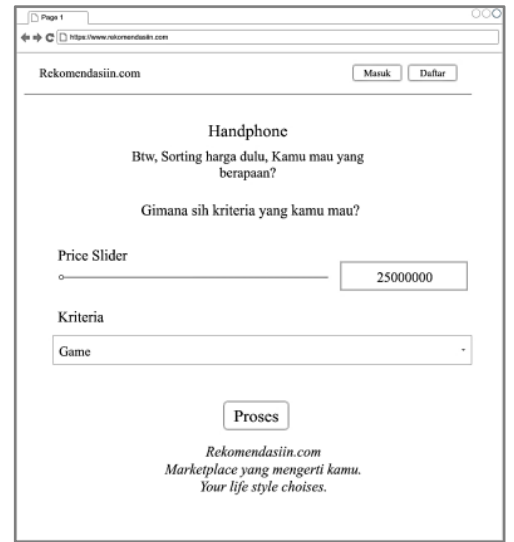

Gambar 4. Rancangan pemilihan kriteria 


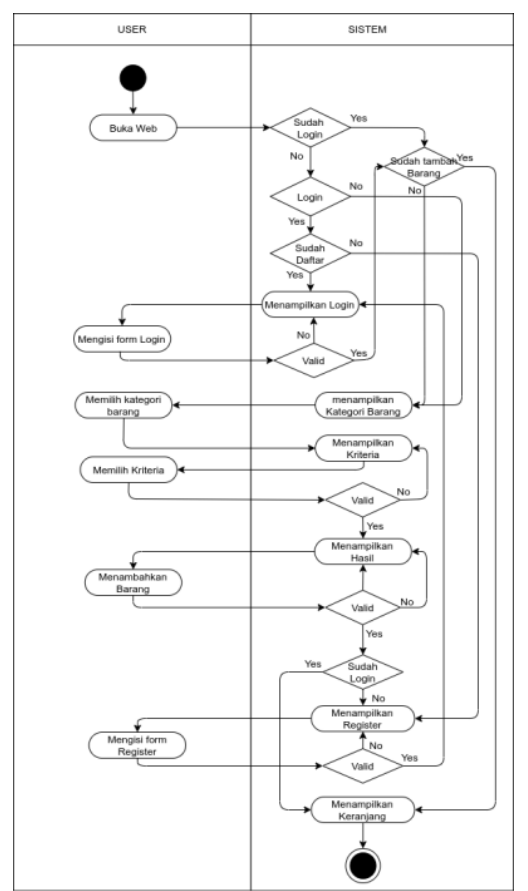

Gambar 5. Activity pemilihan barang

Gambar diatas merupakan activity diagram pemilihan barang dari rekomendasiin.com mulai dari pertama user membuka web hingga memasukan ke keranjang.

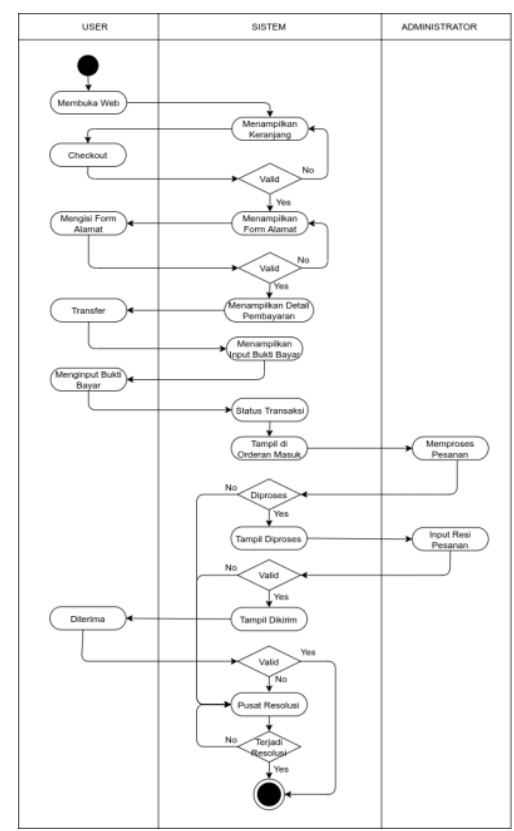

Gambar 6. Activity Transaksi

Gambar diatas merupakan activity diagram transaksi dari rekomendasiin.com mulai dari user memasukan barang hingga barang diterima user.

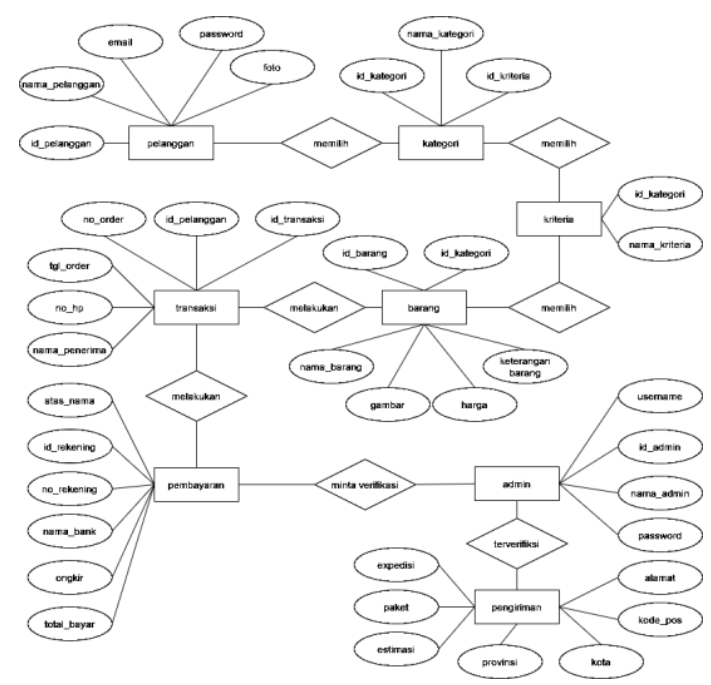

Gambar 7. Diagram database dengan ERD

Gambar diatas merupakan diagram hubungan antara entity dari rekomendasiin.com

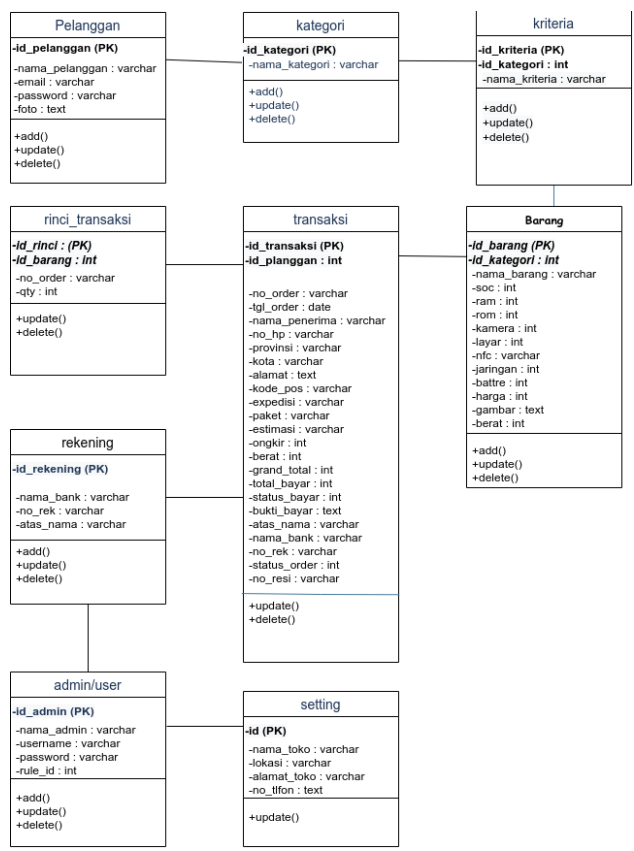

Gambar 8. Diagram database dengan LRS

Gambar diatas merupakan Logical Relational Structur dari rekomendasiin.com yang mana menggambarkan fisik database yang dibuat. 
Tabel 12. Pengujian pelilihan Barang

\begin{tabular}{|c|c|c|c|c|c|}
\hline \multicolumn{5}{|c|}{ Tabel Pengujian Blackbox - Melihat barang / Perekomendasian } \\
\hline o & $\begin{array}{c}\text { Sekenario } \\
\text { Pengujian }\end{array}$ & Test Case & Tujuan & Hasil & Kesimpulan \\
\hline & $\begin{array}{c}\text { Mengisi } \\
\text { range harga } \\
\text { terlalu } \\
\text { rendah atau } \\
\text { tinggi }\end{array}$ & $\begin{array}{c}\text { Harga : 0 dan } \\
15.000 .000\end{array}$ & $\begin{array}{c}\text { Error } \\
\text { Barang } \\
\text { Tidak } \\
\text { Tersedia }\end{array}$ & $\begin{array}{c}\text { Sesuai yang } \\
\text { diharapkan }\end{array}$ & Valid \\
\hline & $\begin{array}{c}\text { Mengisi } \\
\text { semua } \\
\text { sesuai } \\
\text { dengan } \\
\text { yang } \\
\text { diminta }\end{array}$ & $\begin{array}{c}\text { Harga : 2500000 } \\
\text { Banyak Hasil : } 3 \\
\text { Kriteria: } \\
\text { Fotografi }\end{array}$ & $\begin{array}{c}\text { Tampil } \\
\text { hasil yang } \\
\text { di } \\
\text { harapkan }\end{array}$ & $\begin{array}{c}\text { Sesuai yang } \\
\text { diharapkan }\end{array}$ & Valid \\
& & & \\
& & & \\
\end{tabular}

Tabel 13. Pengujian Checkout

\begin{tabular}{|c|c|c|c|c|c|}
\hline \multicolumn{6}{|c|}{ Tabel Pengujian Blackbox - Form Checkout } \\
\hline No & $\begin{array}{l}\text { Sekenario } \\
\text { Pengujian }\end{array}$ & Test Case & Tujuan & Hasil & Kesimpulan \\
\hline 1 & $\begin{array}{c}\text { Mengosongkan } \\
\text { salah satu } \\
\text { kolom dalam } \\
\text { form checkout }\end{array}$ & $\begin{array}{c}\text { Penerima, } \\
\text { No } \\
\text { Handphone, } \\
\text { Provinsi, } \\
\text { Kota, } \\
\text { Expedisi, } \\
\text { paket, } \\
\text { alamat, dan } \\
\text { kode pos } \\
\text { ada yang } \\
\text { tidak diisi }\end{array}$ & $\begin{array}{c}\text { Sistem } \\
\text { tidak akan } \\
\text { memproses } \\
\text { checkout }\end{array}$ & $\begin{array}{c}\text { Sesuai } \\
\text { yang } \\
\text { diharapkan }\end{array}$ & Valid \\
\hline 2 & $\begin{array}{c}\text { Mengisi semua } \\
\text { sesuai dengan } \\
\text { yang diminta }\end{array}$ & $\begin{array}{c}\text { Penerima, } \\
\text { No } \\
\text { Handphone, } \\
\text { Provinsi, } \\
\text { Kota, } \\
\text { Expedisi, } \\
\text { paket, } \\
\text { alamat, dan } \\
\text { kode pos } \\
\text { terisi }\end{array}$ & $\begin{array}{c}\text { Sistem } \\
\text { akan } \\
\text { memproses } \\
\text { checkout }\end{array}$ & $\begin{array}{c}\text { Sesuai } \\
\text { yang } \\
\text { diharapkan }\end{array}$ & Valid \\
\hline
\end{tabular}

Hasil implementasi berupa website dengan $u r l \mathrm{https}: / /$ rekomendasiin.com dan aplikasi android yang bisa diunduh melalui https://s.id/F7yZx

1) Hasil implementasi - Website

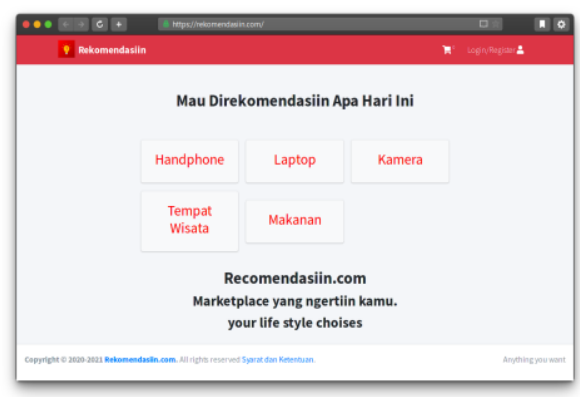

Gambar 9. Halaman depan website rekomendasiin.com

Gambar diatas merupakan hasil penerapan dari dari rekomendasiin.com untuk web
2) Hasil implementasi - Aplikasi Android

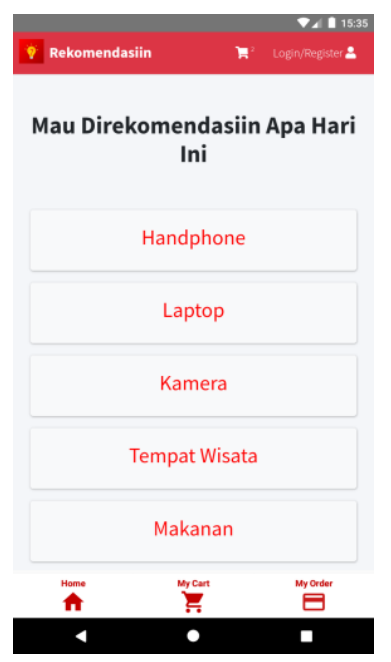

Gambar 10. Halaman aplikasi rekomendasiin

Gambar diatas merupakan hasil penerapan dari dari rekomendasiin.com untuk perangkat android

\section{Kesimpulan}

Setiap orang mempunyai keinginan yang berbeda, berbeda juga kebutuhan dari setiap keingginan tersebut terutama dalam pemilihan produk IT. Dengan menggunakan teknologi algoritma sistim pendukung keputusan dengan metode simple additive weighting dalam sebuah e-commerce serta pemilihan model bisnis stratup dengan Business model canvassing maka akan mendapatkah hasil.

1. Pemilihan barang yang sesuai kebutuhan

2. Pencocokan untuk setiap kebutuhan yang berbeda

3. Memudahkan dalam pembelian barang dalam ecommerce tersebut

4. Dan penentuan value dari sebuah startup dari bmc tersebut.

\section{Daftar Pustaka}

[1] Y. W. Syaifudin, A. F. Syafiandini, and H. R. Prisadana, "APLIKASI PENCARIAN PENJUALAN LAPTOP MENGGUNAKAN TEKNOLOGI WEB SCRAPING," J. Inform. Polinema, vol. 4, no. 4, p. 246, Aug. 2018, doi: 10.33795/jip.v4i4.214.

[2] M. R. Noviansyah, W. Suharso, D. R. Chandranegara, M. S. Azmi, and M. Hermawan, "Sistem Pendukung Keputusan Pemilihan Laptop Pada E- 
Commerce Menggunakan Metode Weighted Product," Pros. SENTRA (Seminar Teknol. dan Rekayasa), vol. 0, no. 5, pp. 43-53, 2019, [Online]. Available: http://research-

report.umm.ac.id/index.php/sentra/article/ view/3025.

[3] A. T. Syauqi, "Startup sebagai Digitalisasi Ekonomi dan Dampaknya bagi Ekonomi Kreatif di Indonesia," Dep. Electr. Eng. Inf. Technol., pp. 1-4, 2016.

[4] B. Unhelkar, Software Engineering with UML. Auerbach Publications, Imprint of Warren, Gorham and Lamont 31 St. James Avenue Boston, MAUnited States, 2018.

[5] R. Taufiq, A. A. Permana, T. Cahyanto, and R. Adha, "Sistem Pendukung Keputusan Penerimaan Karyawan Menggunakan Simple Additive Weighting Studi Kasus PT. Trafoindo Prima Perkasa," J. Al-AZHAR Indones. SERI SAINS DAN Teknol., vol. 4, no. 4, p. 186, 2018, doi: 10.36722/sst.v4i4.309.

[6] A. Osterwalder and Y. Pigneur, Business Model Generation: A Handbook for Visionaries, Game Changers, and Challengers. Hoboken, New Jersey.: John Wiley \& Sons, Inc., 2010. 